\title{
Factors affecting the development of long-term relationships among SME entrepreneurs in the Malaysian agro-based industry
}

\begin{abstract}
A strategy based on long-term relationships is considered one of the most effective options, especially for small and medium enterprises (SMEs), to be competitive and sustainable in the market. There are many benefits that can be obtained from long-term relationships that include efficiency and effectiveness in operations, total cost reduction, better delivery performance, and higher profit. Thus, the objective of this study is to determine factors that influence the development of long-term relationships among SME entrepreneurs in the Malaysian agro-based industry. The data collected from 226 entrepreneurs has revealed 7 important factors that influence the development of long-term relationships of SME entrepreneurs with their preferred buyers. These factors were trust, reputation, quality, satisfaction, power/dependence, relationship specific investments and communication. This result provides a basis for managers to put more effort into developing business relationships in order to create high competitive advantage in the market.
\end{abstract}

Keyword: Agro-based industry; Buyer-seller; Long-term relationship; SMEs 